\title{
Article
}

\section{The Association between Vitamin D and Nonalcoholic Fatty Liver Disease Assessed by Controlled Attenuation Parameter}

\author{
Nam Ju Heo ${ }^{1}$, Hyo Eun Park ${ }^{2}{ }^{\circledR}$, Ji Won Yoon ${ }^{3}$, Min-Sun Kwak ${ }^{4}$, Jong In Yang ${ }^{4}$, Su Jin Chung ${ }^{4}$, \\ Jeong Yoon Yim ${ }^{4}$ and Goh Eun Chung $4, *(\mathbb{D}$ \\ 1 Department of Nephrology, Internal Medicine, Seoul National University Hospital Healthcare System \\ Gangnam Center, Seoul 06236, Korea; julie082007@naver.com \\ 2 Department of Cardiology, Internal Medicine, Seoul National University Hospital Healthcare System \\ Gangnam Center, Seoul 06236, Korea; hyoeunmd1@gmail.com \\ 3 Department of Endocrinology, Internal Medicine, Seoul National University Hospital Healthcare System \\ Gangnam Center, Seoul 06236, Korea; jwyoonmd@gmail.com \\ 4 Department of Gastroenterology and Hepatology, Internal Medicine, Seoul National University Hospital \\ Healthcare System Gangnam Center, Seoul 03080, Korea; kms39@snuh.org (M.-S.K.); \\ drmirinae@snuh.org (J.I.Y.); medjsj@snuh.org (S.J.C.); yjy@snuh.org (J.Y.Y.) \\ * Correspondence: gohwom@snu.ac.kr; Tel.: +82-(0)2-2112-5741; Fax: +82-(0)2-2112-5635
}

Citation: Heo, N.J.; Park, H.E.; Yoon, J.W.; Kwak, M.-S.; Yang, J.I.; Chung, S.J.; Yim, J.Y.; Chung, G.E. The Association between Vitamin D and Nonalcoholic Fatty Liver Disease Assessed by Controlled Attenuation Parameter. J. Clin. Med. 2021, 10, 2611. https://doi.org/10.3390/jcm10122611

Academic Editor: Yulia A. Nevzorova

Received: 2 June 2021

Accepted: 11 June 2021

Published: 13 June 2021

Publisher's Note: MDPI stays neutral with regard to jurisdictional claims in published maps and institutional affiliations.

Copyright: (c) 2021 by the authors. Licensee MDPI, Basel, Switzerland. This article is an open access article distributed under the terms and conditions of the Creative Commons Attribution (CC BY) license (https:// creativecommons.org/licenses/by/ $4.0 /)$.

\begin{abstract}
Background: An association between nonalcoholic fatty liver disease (NAFLD) and low vitamin D levels has been suggested. We investigated the relationship between vitamin D and NAFLD assessed by controlled attenuation parameter (CAP). Methods: We conducted a retrospective cohort study of apparently healthy subjects who underwent Fibroscan during health screening tests. NAFLD was diagnosed using CAP values. Results: Among the 1202 subjects (mean age 57.2 years, $60.6 \%$ male), 630 (52.4\%) subjects had NAFLD with CAP $\geq 248 \mathrm{~dB} / \mathrm{m}$. Multivariable analysis was conducted after adjusting for metabolic risk factors including diabetes, hypertension, hypercholesterolemia, body mass index, high-density lipoprotein cholesterol, triglyceride and smoking. Higher vitamin D levels showed a lower risk of NAFLD compared to the lowest quartile of vitamin D in a dose-dependent manner (OR 0.68, 95\% CI 0.47-1.00 in Q2 vs. Q1; OR 0.65, 95\% CI $0.44-0.94$ in Q3 vs. Q1; and OR 0.64, 95\% CI 0.44-0.94 in Q4 vs. Q1). The highest quartile of vitamin D showed a decreased risk of a severe grade of steatosis (CAP $\geq 302 \mathrm{~dB} / \mathrm{m}$ ) compared to the lowest quartile (OR 0.52, 95\% CI 0.31-0.87 in Q4 vs. Q1). Conclusions: Higher levels of serum vitamin D were associated with a decreased risk of CAP-defined NAFLD, compared to low levels of serum vitamin $D$. The association between NAFLD and vitamin D suggests that vitamin D may exert a protective role against NAFLD.
\end{abstract}

Keywords: vitamin D; hepatic steatosis; CAP

\section{Introduction}

Non-alcoholic fatty liver disease (NAFLD) is the most common liver disease, with a prevalence of $25 \%$ globally and $27 \%$ in Asia [1]. NAFLD is closely related to various metabolic conditions, such as visceral obesity, type 2 diabetes and cardiovascular disease, and has been regarded as a hepatic manifestation of metabolic syndrome [2]. Recently, the new definition as 'metabolic (dysfunction)-associated fatty liver disease (MAFLD)' has been introduced, and there is an emphasis on the role of metabolic dysfunction on the clinical outcome of patients with fatty liver disease [3]. Although liver biopsy is the gold standard for diagnosis and quantitation of fatty liver, its use in clinical practice, especially in asymptomatic subjects without overt liver disease, is extremely limited due to its invasiveness and possible sampling error. Therefore, ultrasonography is recommended as the first-line modality in clinical practices [4]. In addition to imaging modalities, a controlled attenuation parameter (CAP) during transient elastography using FibroScan ${ }^{\circledR}$ 
has high sensitivity in detecting low-grade steatosis and a good correlation with grades of steatosis. Thus, CAP can be used to assess hepatic steatosis while enabling early and noninvasive detection of NAFLD at the subclinical stage [5-7].

Vitamin D is a sterol derivative synthesized by ultraviolet radiation from the skin and can also be obtained from the diet or food supplements. As a fat-soluble vitamin, it affects bone metabolism and immune function [8]. Vitamin D deficiency, characterized by low serum levels of 25-hydroxyvitamin $\mathrm{D}$, is associated with the increased risk of various metabolic diseases, including metabolic syndrome [9,10], coronary artery disease [11] and chronic liver disease $[8,12]$. The association between vitamin D deficiency and NAFLD has been examined in previous studies. A lower vitamin $\mathrm{D}$ was an independent risk factor for NAFLD [13,14] and a predictor of the severity of NAFLD [15]. Rhee et al. reported that participants with higher vitamin D showed a significantly reduced risk for NAFLD [16]. A recent meta-analysis displayed a negative association between serum vitamin $\mathrm{D}$ levels and NAFLD, with a lower odds ratio $(\mathrm{OR})=0.64$ [17]. However, several studies reported that serum vitamin D might not be associated with the histologic severity of NAFLD [18,19].

Based on a study of a health check-up population, we evaluated the association between vitamin D and NAFLD/MAFLD, defined by CAP using FibroScan ${ }^{\circledR}$, which gives an objective value for early diagnosis of hepatic steatosis and fibrosis.

\section{Methods}

\subsection{Study Population}

This retrospective observational study included subjects who underwent routine health check-ups at the Seoul National University Hospital Healthcare System Gangnam Center between January 2018 and December 2020. The subjects underwent general health check-ups on a voluntary basis or through employer-sponsored coverage. The subjects were mostly free of symptoms and willingly received examinations including, FibroScan ${ }^{\circledR}$ (Echosens, Paris, France) and blood samplings on the same day. Initially, a total of 1417 subjects were enrolled. For NAFLD, subjects who displayed any potential cause of chronic liver disease were excluded; 36 were positive for the hepatitis B virus, 12 were positive for the hepatitis $C$ virus, and 167 had significant alcohol intake $(>20 \mathrm{~g} /$ day for males and $>10 \mathrm{~g} /$ day for females) [20]. As a result, 1202 subjects were included in the NAFLD analysis. For MAFLD, 109 subjects with missing information were excluded. The diagnosis of MAFLD was based on the previous criteria [3].

The study protocol adhered to the guidelines of the Declaration of Helsinki of 1975, as revised in 1983. The protocol was approved by the Institutional Review Board of Seoul National University Hospital (No. 2006-024-1130). Informed consent was waived by the board as researchers accessed and analyzed only de-identified data.

\subsection{Measurement of Anthropometric and Laboratory Parameters}

The methods employed in this study have been previously described in detail [21]. Anthropometric and laboratory parameters were taken on the same day of the health check-ups. Body weight and height were measured using a digital scale, and body mass index (BMI) was calculated by dividing weight $(\mathrm{kg})$ by the squared value of height $\left(\mathrm{m}^{2}\right)$. Well-trained personnel used a measuring tape to measure the waist circumference at the midpoint between the lower costal margin and anterior superior iliac crest.

Data regarding past medical history, comorbidities and medication history were obtained through subject-recorded questionnaires. Each subject was categorized as a smoker or non-smoker, and the amount of alcohol each patient consumed was calculated. Blood pressure was measured at least twice, and mean values of the measurements were recorded. Hypertension was defined as blood pressure $\geq 140 / 90 \mathrm{mmHg}$ or receiving antihypertensive medications. Diabetes was defined as fasting blood glucose $\geq 126 \mathrm{mg} / \mathrm{dL}$ or receiving glucose-lowering agents. Subjects taking lipid-lowering agents were categorized as having hypercholesterolemia [21]. All blood samples were collected after a 12-h overnight fast. Laboratory tests included serum total cholesterol, triglycerides, high-density lipopro- 
tein (HDL) cholesterol, fasting glucose, creatinine and high-sensitivity C-reactive protein (HS-CRP). Standard laboratory methods were used to perform all of these tests.

\subsection{Measurement of Serum Vitamin D Levels}

Serum levels of 25-hydroxyvitamin $(\mathrm{OH}) \mathrm{D}_{3}$ were measured using a chemiluminescence immunoassay kit (Diasorin, Stillwater, OK, USA). Subjects were categorized as having either vitamin D deficiency $(<20 \mathrm{ng} / \mathrm{mL})$ or vitamin D sufficiency $(\geq 20 \mathrm{ng} / \mathrm{mL})[22,23]$. Additionally, quartile 1 of serum vitamin D level was $\leq 14.6 \mathrm{ng} / \mathrm{mL}$, quartile 2 was 14.7$19.5 \mathrm{ng} / \mathrm{mL}$, quartile 3 was $19.6-26.7 \mathrm{ng} / \mathrm{mL}$, and quartile 4 was $\geq 26.8 \mathrm{ng} / \mathrm{mL}$. We used the lowest quartile $(\leq 14.4 \mathrm{ng} / \mathrm{mL})$ of vitamin D levels as a reference group.

\subsection{Measurement of NAFLD Using CAP and Liver Stiffness}

CAP and liver stiffness measurements (LSM) were obtained by FibroScan ${ }^{\circledR}$ using an $\mathrm{M}$ or XL probe (Echosens, Paris, France). The procedure was performed by an experienced investigator who was blinded to the patients' clinical information. The procedure was performed as described briefly [24]. The patient was positioned in dorsal decubitus with the right arm maximally abducted. FibroScan ${ }^{\circledR}$ was performed on the right lobe through the intercostal spaces. The median LSM values were expressed in kilopascals $(\mathrm{kPa})$, and the median CAP was expressed in $\mathrm{dB} / \mathrm{m}$. LSM values were considered reliable if 10 valid measurements were obtained and the interquartile range/median of the measurements were $<0.3$ or when the LS median was $<7.1 \mathrm{kPa}$ [25]. All of the patients with 10 valid shots were included in the analysis. In this study, CAP values of 248 and $302 \mathrm{~dB} / \mathrm{m}$ were used to define NAFLD and grade the steatosis $[7,26]$.

\subsection{Statistical Analysis}

Continuous variables were expressed as mean \pm SD for normally distributed continuous variables, and categorical variables were expressed in number and percentage. To test for normality, the Kolmogorov-Smirnov test and the normal Q-Q plots were used. For non-normally distributed variables, log transformations were performed. Comparisons between normal and low vitamin D groups were performed using Student's t-test for continuous variables and the chi-square test or Fisher's exact test for categorical variables. To evaluate the parameters that affect NAFLD, univariate and multivariate logistic regression analyses were performed. Model 1 was adjusted for age, sex, hypertension, diabetes, hypercholesterolemia and BMI. Model 2 was further adjusted for HDL-cholesterol, triglyceride and smoking. All statistical analyses were performed using SPSS 22.0 (SPSS Inc., Chicago, IL, USA), and $p$ values $<0.05$ were considered statistically significant.

\section{Results}

\subsection{Clinical Characteristics of Study Population}

The mean age of our study population was 57.2 years, and $60.6 \%$ of the subjects were male. Among the 1202 subjects, 614 (51.1\%) displayed vitamin D deficiency. Clinical characteristics according to vitamin D level are summarized in Table 1. Compared with those with vitamin $\mathrm{D}$ sufficiency, individuals with vitamin $\mathrm{D}$ deficiency were younger, more frequently obese (BMI $\geq 25$ ), current smokers and had a higher waist circumference $(p<0.05)$. Serum levels of total cholesterol and triglyceride were higher, while serum levels of HDL-cholesterol were lower in individuals with vitamin D deficiency than those with vitamin D sufficiency. Subjects with vitamin D deficiency had a higher prevalence of NAFLD for both CAP $\geq 248$ and $\geq 302 \mathrm{~dB} / \mathrm{m}(p<0.05)$. The tertiles of LSM value were not different between the two groups. 
Table 1. A comparison of baseline characteristics according to vitamin D level.

\begin{tabular}{|c|c|c|c|}
\hline & $\begin{array}{l}\text { Vitamin D Sufficiency } \\
(\geq 20 \mathrm{ng} / \mathrm{mL}) \\
(n=588)\end{array}$ & $\begin{array}{l}\text { Vitamin D Deficiency } \\
(<20 \mathrm{ng} / \mathrm{mL}) \\
(n=614)\end{array}$ & $p$-Value \\
\hline Age (years) & $59.0 \pm 10.3$ & $55.5 \pm 10.8$ & $<0.001$ \\
\hline Male, $n(\%)$ & $355(60.4)$ & $374(60.9)$ & 0.849 \\
\hline Current smoking, $n(\%)$ & $94(16.0)$ & $136(22.1)$ & 0.007 \\
\hline BMI $\left(\mathrm{kg} / \mathrm{m}^{2}\right)$ & $24.0 \pm 3.3$ & $24.7 \pm 3.6$ & 0.707 \\
\hline $\mathrm{BMI} \geq 25\left(\mathrm{~kg} / \mathrm{m}^{2}\right)$ & $207(35.2)$ & $262(42.7)$ & 0.008 \\
\hline Waist circumference $(\mathrm{cm})$ & $87.7 \pm 9.2$ & $88.9 \pm 9.9$ & 0.036 \\
\hline Systolic blood pressure, $\mathrm{mmHg}$ & $122.1 \pm 16.3$ & $122.1 \pm 16.5$ & 0.972 \\
\hline Diastolic blood pressure, $\mathrm{mmHg}$ & $80.4 \pm 10.7$ & $81.3 \pm 10.9$ & 0.149 \\
\hline \multicolumn{4}{|l|}{ Comorbidities } \\
\hline Diabetes mellitus, $n(\%)$ & $110(18.7)$ & $102(16.6)$ & 0.341 \\
\hline Hypertension, $n(\%)$ & $183(31.1)$ & $169(27.5)$ & 0.171 \\
\hline Hypercholesterolemia, $n(\%)$ & $190(32.3)$ & $145(23.5)$ & 0.002 \\
\hline \multicolumn{4}{|l|}{ Laboratory parameters } \\
\hline Total cholesterol (mg/dL) & $188.5 \pm 40.1$ & $194.5 \pm 40.9$ & 0.010 \\
\hline Triglyceride $(\mathrm{mg} / \mathrm{dL})^{+}$ & $97(68-137)$ & $97(70-149)$ & 0.041 \\
\hline HDL-cholesterol (mg/dL) & $55.8 \pm 15.1$ & $53.9 \pm 15.0$ & 0.031 \\
\hline Fasting glucose $(\mathrm{mg} / \mathrm{dL})$ & $104.8 \pm 22.1$ & $105.9 \pm 24.4$ & 0.412 \\
\hline Creatinine $(\mathrm{mg} / \mathrm{dL})$ & $0.85 \pm 0.2$ & $0.84 \pm 0.2$ & 0.786 \\
\hline HS-CRP (mg/dL) & $0.13 \pm 0.3$ & $0.15 \pm 0.4$ & 0.297 \\
\hline \multicolumn{4}{|l|}{ Transient elastography } \\
\hline Controlled attenuation parameter, $\mathrm{dB} / \mathrm{m}^{+}$ & $246(215-285)$ & $258(217-300)$ & 0.005 \\
\hline $\mathrm{CAP} \geq 248$ & $287(48.8)$ & $343(55.9)$ & 0.014 \\
\hline $\mathrm{CAP} \geq 302$ & $99(16.8)$ & $144(23.5)$ & 0.004 \\
\hline Liver stiffness measurement, $\mathrm{kPa}^{+}$ & $3.6(3.1-4.4)$ & $4.2(3.5-4.8)$ & 0.851 \\
\hline Tertile $1(<3.4)$ & $195(33.2)$ & $194(31.6)$ & 0.359 \\
\hline Tertile $2(3.4-4.2)$ & $208(35.4)$ & $203(33.1)$ & \\
\hline Tertile $3(\geq 4.3)$ & $185(31.5)$ & $217(35.3)$ & \\
\hline
\end{tabular}

Data are shown as the mean $\pm \mathrm{SD} .{ }^{+}$median (interquartile range). BMI, body mass index; $\mathrm{CAP}$, controlled attenuation parameter; HDL, high-density lipoprotein; HS-CRP, high sensitivity C-reactive protein.

\subsection{Parameters Associated with NAFLD}

Table 2 shows the association of each parameter with NAFLD defined by CAP $\geq 248 \mathrm{~dB} / \mathrm{m}$ using univariate logistic regression analysis. Male sex, hypertension, diabetes, hypercholesterolemia, smoking, BMI, fasting glucose, triglyceride and HDL-cholesterol were significantly associated with NAFLD $(p<0.05)$. The serum vitamin D levels ( $\geq 20$ (vs. $<20 \mathrm{ng} / \mathrm{mL})$ ) were inversely associated with NAFLD defined as CAP $\geq 248 \mathrm{~dB} / \mathrm{m}$ (Odds ratio (OR) $0.75,95 \%$ confidence interval (CI) 0.60-0.95). When evaluated in quartiles, the highest quartile of serum vitamin $\mathrm{D}$ was associated with a lower risk of NAFLD compared to the lowest quartile (OR $0.60,95 \%$ CI $0.44-0.83$ in Q4 vs. Q1).

\subsection{Association between NAFLD/MAFLD and Vitamin D Level}

Multivariate logistic regression analysis was performed to evaluate the adjusted association between hepatic steatosis and vitamin D levels. When adjusting for age and sex, individuals with vitamin D sufficiency was associated with decreased risk of NAFLD defined as CAP $\geq 248 \mathrm{~dB} / \mathrm{m}$ compared to those with vitamin D deficiency (OR $0.72,95 \% \mathrm{CI}$ 0.57-0.91). Upon further adjustments of multiple confounding factors including hypertension, diabetes, hypercholesterolemia, BMI, HDL-cholesterol triglyceride and smoking, individuals with vitamin D sufficiency was associated with a lower risk of NAFLD compared to those with vitamin D deficiency without statistical significance (OR 0.78, 95\% CI $0.60-1.02$, Table 3). When we evaluated vitamin D levels in quartiles, the highest quartile 
of vitamin D showed a dose-dependent relationship with NAFLD compared to the lowest quartile after adjusting multiple confounding factors (OR 0.68, 95\% CI 0.47-1.00 in Q2 vs. Q1; OR 0.65, 95\% CI 0.44-0.94 in Q3 vs. Q1 and OR 0.64; 95\% CI 0.44-0.94 in Q4 vs. Q1). Among the eligible 1308 subjects, 44\% showed MAFLD, and when we investigated the association between MAFLD and vitamin D level, although the significance attenuated, the results are similar to that of NAFLD (Table 4).

Table 2. Parameters associated with NAFLD (CAP $\geq 248 \mathrm{~dB} / \mathrm{m})$.

\begin{tabular}{|c|c|c|c|}
\hline Variables & Odds Ratio & 95\% Confidence Interval & $p$-Value * \\
\hline Age, years & 1.01 & $1.00-1.02$ & 0.220 \\
\hline Male & 2.30 & $1.82-2.92$ & $<0.001$ \\
\hline Hypertension & 1.62 & $1.26-2.08$ & $<0.001$ \\
\hline Diabetes mellitus & 1.52 & $1.07-2.15$ & 0.020 \\
\hline Hypercholesterolemia & 1.50 & $1.16-1.93$ & 0.002 \\
\hline Smoking & 1.79 & $1.33-2.41$ & $<0.001$ \\
\hline Body mass index, $\mathrm{kg} / \mathrm{m}^{2}$ & 1.29 & $1.24-1.34$ & $<0.001$ \\
\hline $\mathrm{BMI} \geq 25, \mathrm{~kg} / \mathrm{m}^{2}$ & 5.66 & $4.36-7.36$ & $<0.001$ \\
\hline Fasting glucose, mg/dL & 1.02 & $1.01-1.03$ & $<0.001$ \\
\hline Total cholesterol, mg/dL & 1.00 & $1.00-1.00$ & 0.420 \\
\hline Triglyceride, mg/dL + & 5.03 & $3.85-6.58$ & $<0.001$ \\
\hline HDL cholesterol, mg/dL & 0.96 & $0.95-0.97$ & $<0.001$ \\
\hline HS-CRP (mg/dL) & 1.29 & $0.89-1.87$ & 0.176 \\
\hline $\begin{array}{l}\text { Vitamin } D \geq 20(\text { vs. } \\
\quad<20)(\mathrm{ng} / \mathrm{mL})\end{array}$ & 0.75 & $0.60-0.95$ & 0.014 \\
\hline \multicolumn{4}{|l|}{ Vitamin D Quartile } \\
\hline 1st $(-14.6)$ & 1 (reference) & & $0.019^{* *}$ \\
\hline 2nd (14.7-19.5) & 0.82 & $0.59-1.13$ & 0.218 \\
\hline 3rd (19.6-26.7) & 0.73 & $0.53-1.01$ & 0.056 \\
\hline 4th (26.8-) & 0.60 & $0.44-0.83$ & 0.002 \\
\hline
\end{tabular}

BMI, body mass index; CAP, controlled attenuation parameter; HDL, high-density lipoprotein; HS-CRP, high sensitivity C-reactive protein. ${ }^{*}$ compared to no NAFLD, ${ }^{* *} p$ for trends, ${ }^{+} \log$ transformed.

Table 3. Multivariate analysis for the association between vitamin D and hepatic steatosis.

\begin{tabular}{|c|c|c|c|c|c|c|}
\hline \multirow{2}{*}{ Vitamin D } & \multicolumn{2}{|c|}{ Age, Sex Adjusted } & \multicolumn{2}{|c|}{ Multivariate Model I } & \multicolumn{2}{|c|}{ Multivariate Model II } \\
\hline & OR (95\% CI) & $p$-Value & OR (95\% CI) & $p$-Value & OR (95\% CI) & $p$-Value \\
\hline$\geq 20$ (vs. $<20 \mathrm{ng} / \mathrm{mL}$ ) & $0.72(0.57-0.91)$ & 0.007 & $0.79(0.60-1.00)$ & 0.051 & $0.78(0.60-1.02)$ & 0.069 \\
\hline \multicolumn{7}{|l|}{ Quartile } \\
\hline 1st (-14.6) & 1 (reference) & $0.006^{*}$ & 1 (reference) & $0.037^{*}$ & 1 (reference) & $0.065^{*}$ \\
\hline 2nd (14.7-19.5) & $0.73(0.52-1.02)$ & 0.062 & $0.70(0.49-0.99)$ & 0.046 & $0.68(0.47-1.00)$ & 0.049 \\
\hline 3rd (19.6-26.7) & $0.62(0.45-0.87)$ & 0.005 & $0.66(0.46-0.95)$ & 0.024 & $0.65(0.44-0.94)$ & 0.022 \\
\hline 4th (26.8-) & $0.57(0.41-0.80)$ & 0.001 & $0.61(0.43-0.87)$ & 0.007 & $0.64(0.44-0.94)$ & 0.021 \\
\hline
\end{tabular}

CI, confidence interval; OR, odds ratio; Model I: Adjusted for age, sex, hypertension, diabetes, hypercholesterolemia and body mass index. Model II: Model I plus high-density lipoprotein cholesterol, triglyceride and smoking. ${ }^{*} p$ for trends.

Table 4. Multivariate analysis for the association between vitamin D and MAFLD.

\begin{tabular}{ccccccc}
\hline \multirow{2}{*}{ Vitamin D } & \multicolumn{2}{c}{ Unadjusted } & \multicolumn{2}{c}{ Age, Sex and Smoking Adjusted } & \multicolumn{2}{c}{ Multivariate Model } \\
\cline { 2 - 6 } & OR (95\% CI) & $p$-Value & OR (95\% CI) & $p$-Value & OR (95\% CI) & $p$-Value \\
\hline$\geq 20($ vs. $<20 \mathrm{ng} / \mathrm{mL})$ & $0.73(0.59-0.91)$ & 0.005 & $0.72(0.57-0.90)$ & 0.005 & $0.78(0.59-1.03)$ & 0.079 \\
\hline Quartile & & & & & \\
\hline
\end{tabular}


Table 4. Cont.

\begin{tabular}{ccccccc}
\hline \multirow{2}{*}{ Vitamin D } & \multicolumn{2}{c}{ Unadjusted } & \multicolumn{2}{c}{ Age, Sex and Smoking Adjusted } & \multicolumn{2}{c}{ Multivariate Model } \\
\cline { 2 - 7 } & OR (95\% CI) & $p$-Value & OR (95\% CI) & $p$-Value & OR (95\% CI) & $p$-Value \\
\hline 1st (-14.6) & 1 (reference) & $0.006^{*}$ & 1 (reference) & $0.015^{*}$ & 1 (reference) & $0.167^{*}$ \\
2nd (14.7-19.5) & $0.97(0.71-1.31)$ & 0.829 & $0.87(0.64-1.20)$ & 0.403 & $0.74(0.50-1.09)$ & 0.123 \\
3rd (19.6-26.7) & $0.85(0.63-1.16)$ & 0.31 & $0.74(0.54-1.02)$ & 0.069 & $0.69(0.47-1.03)$ & 0.066 \\
4th (26.8-) & $0.60(0.44-0.82)$ & 0.001 & $0.60(0.43-0.83)$ & 0.002 & $0.67(0.45-0.99)$ & 0.046 \\
\hline
\end{tabular}

CI, confidence interval; OR, odds ratio; MAFLD, metabolic dysfunction-associated fatty liver disease. Adjusted for age, sex, smoking, waist circumference, systolic blood pressure, triglyceride and high sensitivity C-reactive protein. ${ }^{*} p$ for trends.

\subsection{Association between Grade of Steatosis and Vitamin D Level}

To evaluate the association between the grade of hepatic steatosis and vitamin D levels, we graded hepatic steatosis according to the CAP values $(<248,248-302$ and $\geq 302 \mathrm{~dB} / \mathrm{m})$. The prevalence of vitamin D sufficiency $(\geq 20 \mathrm{ng} / \mathrm{mL})$ was significantly lower in the group with a severe grade of steatosis (CAP $\geq 302 \mathrm{~dB} / \mathrm{m}$ ) compared to the group with $\mathrm{CAP}>248 \mathrm{~dB} / \mathrm{m}(p=0.008$, Figure 1$)$. When we performed multivariate ordinary regression analysis, the highest quartile of vitamin $\mathrm{D}$ showed a decreased risk of a severe grade of steatosis ( $\mathrm{CAP} \geq 302 \mathrm{~dB} / \mathrm{m}$ ) compared to the lowest quartile after adjusting multiple confounding factors (OR 0.52, 95\% CI 0.31-0.87 in Q4 vs. Q1, Table 5).

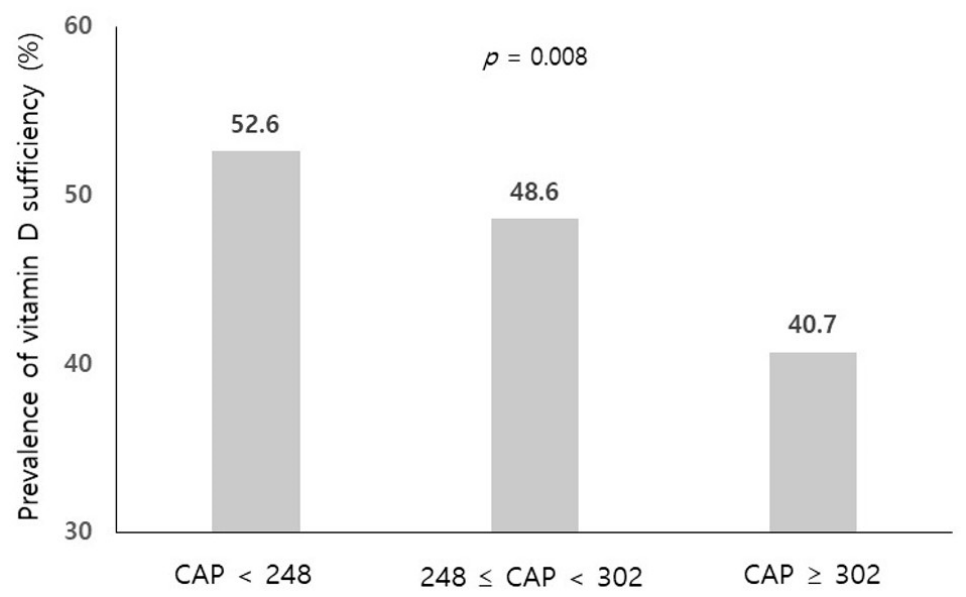

Figure 1. The prevalence of vitamin D sufficiency $(\geq 20 \mathrm{ng} / \mathrm{mL})$ according to the grade of hepatic steatosis. Compared using chi-square test. CAP, controlled attenuation parameter.

Table 5. Multivariate analysis for the association between grade of hepatic steatosis and vitamin D.

\begin{tabular}{ccccc}
\hline \multirow{2}{*}{ Reference (CAP < 248) } & \multicolumn{2}{c}{$\mathbf{2 4 8} \leq$ CAP $<302$} & \multicolumn{2}{c}{ CAP $\geq 302$} \\
\cline { 2 - 5 } & OR (95\% CI) & $p$-Value & OR (95\% CI) & $p$-Value \\
\hline Vitamin D Quartile & & & & \\
\hline 1st (-14.6) & 1 (reference) & & (reference) & \\
2nd (14.7-19.5) & $0.68(0.45-1.03)$ & 0.069 & $0.69(0.42-1.11)$ & 0.127 \\
3rd (19.6-26.7) & $0.66(0.44-0.99)$ & 0.044 & $0.63(0.38-1.02)$ & 0.059 \\
4th (26.8-) & $0.71(0.47-1.06)$ & 0.091 & $0.52(0.31-0.87)$ & 0.013 \\
\hline
\end{tabular}

CAP, controlled attenuation parameter; $\mathrm{CI}$, confidence interval; OR, odds ratio. Adjusted for age, sex, hypertension, diabetes, hypercholesterolemia, body mass index, high-density lipoprotein cholesterol, triglyceride and smoking.

\section{Discussion}

To the best of our knowledge, this is the first study to reveal a decreased risk of CAP-defined NAFLD in subjects with higher vitamin D compared to those with lower vitamin D. Moreover, there was a dose-response relationship between the grade of hepatic steatosis and vitamin D levels. 
Several studies have shown that the prevalence of vitamin D deficiency in patients with NAFLD is higher than in healthy controls $[15,27]$. Recently, NAFLD has been renamed as metabolic dysfunction-associated fatty liver disease, and its association with vitamin $\mathrm{D}$ has been investigated [28]. In their study, NAFLD was usually diagnosed with abdominal ultrasonography. Although ultrasonography is a good modality to detect moderate-severe fatty liver, ultrasonography sensitivity decreases as the hepatic fatty infiltration decreases. In the presence of liver fat content below $20 \%$, ultrasonography sensitivity was only $55 \%$ [4]. In addition, there are limitations to the reliability of such radiologic evaluations, and future studies should include reliability data such as inter- and intra-observer variations [29]. CAP with FibroScan ${ }^{\circledR}$ has recently been introduced as a noninvasive method that detects and quantifies hepatic steatosis as well as fibrosis simultaneously with adequate sensitivity [26]. A previous study has shown that CAP values are significantly associated with the severity of ultrasonography-diagnosed hepatic steatosis, suggesting that increased CAP could be an early indicator of NAFLD [6]. Moreover, the usefulness of CAP is not limited to the liver. The association between CAP-defined NAFLD and increased arterial stiffness [30], the presence of coronary artery plaques [21] and gastroesophageal reflux disease [31] has been reported, suggesting the role of $\mathrm{CAP}$ as risk stratification for extrahepatic manifestations in patients with NAFLD.

Although there has been no consensus on how to define vitamin D deficiency, the cut points of total serum $25(\mathrm{OH})$ D levels as 20 or $30 \mathrm{ng} / \mathrm{mL}$ were mostly used in previous studies [32,33]. However, the median vitamin D concentration varied among previous studies [18], and Rhee et al. has reported that the prevalence of vitamin D insufficiency was relatively high in Korean adults with a rate of more than $60 \%$ [34]. Therefore, additional categories of vitamin D deficiency or insufficiency are needed regarding the Korean population. This study showed no statistical significance regarding the association of NAFLD and vitamin D levels when the subjects were classified into two vitamin D categories. However, when the vitamin D levels were divided into quartiles, the significant relationship between NAFLD and vitamin D remained in all quartile levels. The tertiles of LSM value and surrogate marker of hepatic fibrosis were not different between the normal and low vitamin D groups in this study. The LSM values of most subjects were within the normal range as the subjects for health check-ups were composed of apparently healthy persons without overt liver disease.

The possible mechanisms linking NAFLD and low vitamin D have not been clearly elucidated. First, vitamin D and liver inflammation: since vitamin D has anti-inflammatory activity, a lower vitamin D level might cause dysfunction of adipose tissue and subsequent chronic inflammation, which may result in the development of NAFLD [35]. In the animal model, rats fed with vitamin D depletion showed greater hepatic steatosis and inflammation compared to the control group [36]. Second, vitamin D and insulin sensitivity: vitamin D insufficiency has been independently associated with metabolic syndrome [37] and insulin resistance [38], which is the key pathophysiology of NAFLD and supplementation of vitamin D has resulted in improving insulin sensitivity [39]. Della Pirgon et al. reported that low vitamin D level was associated with insulin resistance in obese NAFLD patients [40]. Third, it has been reported that vitamin D decreased the activation of hepatic stellate cells, suggesting a potential role to protect against liver fibrosis [41]. However, further studies evaluating the pathogenesis between NAFLD and vitamin D are necessary.

\section{Limitations}

Our study has some limitations. First, its cross-sectional design limits the ability to verify causality. Thus, we could not infer causal relationships from this study. Second, NAFLD was not biopsy-proven in this study. However, CAP measurement constitutes a good non-invasive biomarker of hepatic fat or fatty liver [7], although not in NASH and grading of hepatic steatosis. However, the cut-off values used in this study for grading hepatic steatosis were similar to those reported in the study based on the Korean population [42]. Third, we did not consider seasonal variations of vitamin D levels, sun 
exposure time and calcium or vitamin D supplement use in this study. Lastly, our study population of those who underwent health evaluations upon their own initiative may not represent the majority of the general Korean population, and this may contribute to selection bias.

\section{Conclusions}

There was a decreased risk of CAP-defined NAFLD in subjects with higher vitamin $\mathrm{D}$ compared to those with lower vitamin $\mathrm{D}$ in a dose-dependent manner. The association between NAFLD and vitamin D suggests that vitamin D may exert protective roles against NAFLD.

Author Contributions: Conceptualization, G.E.C.; data curation, H.E.P., J.W.Y., M.-S.K., J.I.Y., S.J.C. and J.Y.Y.; writing-original draft preparation, G.E.C. and N.J.H. All authors have read and agreed to the published version of the manuscript.

Funding: This research received no external funding.

Institutional Review Board Statement: The study protocol followed the guidelines of the Declaration of Helsinki of 1975, as revised in 1983. The protocol was approved by the Institutional Review Board of Seoul National University Hospital (No. 2006-024-1130). Informed consent was waived by the board since researchers accessed and analyzed only de-identified data.

Informed Consent Statement: Not applicable.

Data Availability Statement: The data presented in this study are available on request from the corresponding author.

Acknowledgments: The authors are grateful to Gu Cheol Jung for help with the statistical analysis.

Conflicts of Interest: The authors declare no conflict of interest.

\section{References}

1. Younossi, Z.M.; Koenig, A.B.; Abdelatif, D.; Fazel, Y.; Henry, L.; Wymer, M. Global epidemiology of nonalcoholic fatty liver disease-Meta-analytic assessment of prevalence, incidence, and outcomes. Hepatology 2016, 64, 73-84. [CrossRef]

2. Marchesini, G.; Marzocchi, R. Metabolic syndrome and NASH. Clin. Liver Dis. 2007, 11, 105-117. [CrossRef]

3. Eslam, M.; Newsome, P.N.; Sarin, S.K.; Anstee, Q.M.; Targher, G.; Romero-Gomez, M.; Zelber-Sagi, S.; Wai-Sun Wong, V.; Dufour, J.F.; Schattenberg, J.M.; et al. A new definition for metabolic dysfunction-associated fatty liver disease: An international expert consensus statement. J. Hepatol. 2020, 73, 202-209. [CrossRef] [PubMed]

4. Hernaez, R.; Lazo, M.; Bonekamp, S.; Kamel, I.; Brancati, F.L.; Guallar, E.; Clark, J.M. Diagnostic accuracy and reliability of ultrasonography for the detection of fatty liver: A meta-analysis. Hepatology 2011, 54, 1082-1090. [CrossRef] [PubMed]

5. Myers, R.P.; Pollett, A.; Kirsch, R.; Pomier-Layrargues, G.; Beaton, M.; Levstik, M.; Duarte-Rojo, A.; Wong, D.; Crotty, P.; Elkashab, M. Controlled Attenuation Parameter (CAP): A noninvasive method for the detection of hepatic steatosis based on transient elastography. Liver Int. 2012, 32, 902-910. [CrossRef]

6. Kwak, M.S.; Chung, G.E.; Yang, J.I.; Yim, J.Y.; Chung, S.J.; Jung, S.Y.; Kim, J.S. Clinical implications of controlled attenuation parameter in a health check-up cohort. Liver Int. 2018, 38, 915-923. [CrossRef] [PubMed]

7. Karlas, T.; Petroff, D.; Sasso, M.; Fan, J.G.; Mi, Y.Q.; de Lédinghen, V.; Kumar, M.; Lupsor-Platon, M.; Han, K.H.; Cardoso, A.C.; et al. Individual patient data meta-analysis of controlled attenuation parameter (CAP) technology for assessing steatosis. J. Hepatol. 2017, 66, 1022-1030. [CrossRef] [PubMed]

8. Wang, H.; Chen, W.; Li, D.; Yin, X.; Zhang, X.; Olsen, N.; Zheng, S.G. Vitamin D and chronic diseases. Aging Dis. 2017, 8, 346-353. [CrossRef]

9. Gagnon, C.; Lu, Z.X.; Magliano, D.J.; Dunstan, D.W.; Shaw, J.E.; Zimmet, P.Z.; Sikaris, K.; Ebeling, P.R.; Daly, R.M. Low serum 25-hydroxyvitamin $\mathrm{D}$ is associated with increased risk of the development of the metabolic syndrome at five years: Results from a national, population-based prospective study (The Australian Diabetes, Obesity and Lifestyle Study: AusDiab). J. Clin. Endocrinol. Metab. 2012, 97, 1953-1961. [CrossRef] [PubMed]

10. Akter, S.; Eguchi, M.; Kurotani, K.; Kochi, T.; Kashino, I.; Ito, R.; Kuwahara, K.; Tsuruoka, H.; Kabe, I.; Mizoue, T. Serum 25-hydroxyvitamin D and metabolic syndrome in a Japanese working population: The Furukawa Nutrition and Health Study. Nutrition 2017, 36, 26-32. [CrossRef]

11. Lim, S.; Shin, H.; Kim, M.J.; Ahn, H.Y.; Kang, S.M.; Yoon, J.W.; Choi, S.H.; Kim, K.W.; Song, J.H.; Choi, S.I.; et al. Vitamin D inadequacy is associated with significant coronary artery stenosis in a community-based elderly cohort: The Korean Longitudinal Study on Health and Aging. J. Clin. Endocrinol. Metab. 2012, 97, 169-178. [CrossRef] 
12. Elangovan, H.; Chahal, S.; Gunton, J.E. Vitamin D in liver disease: Current evidence and potential directions. Biochim. Biophys. Acta Mol. Basis Dis. 2017, 1863, 907-916. [CrossRef] [PubMed]

13. Zhai, H.L.; Wang, N.J.; Han, B.; Li, Q.; Chen, Y.; Zhu, C.F.; Chen, Y.C.; Xia, F.Z.; Cang, Z.; Zhu, C.X.; et al. Low vitamin D levels and non-alcoholic fatty liver disease, evidence for their independent association in men in East China: A cross-sectional study (Survey on Prevalence in East China for Metabolic Diseases and Risk Factors (SPECT-China)). Br. J. Nutr. 2016, 115, 1352-1359. [CrossRef]

14. Black, L.J.; Jacoby, P.; She Ping-Delfos, W.C.; Mori, T.A.; Beilin, L.J.; Olynyk, J.K.; Ayonrinde, O.T.; Huang, R.C.; Holt, P.G.; Hart, P.H.; et al. Low serum 25-hydroxyvitamin D concentrations associate with non-alcoholic fatty liver disease in adolescents independent of adiposity. J. Gastroenterol. Hepatol. 2014, 29, 1215-1222. [CrossRef] [PubMed]

15. Dasarathy, J.; Periyalwar, P.; Allampati, S.; Bhinder, V.; Hawkins, C.; Brandt, P.; Khiyami, A.; McCullough, A.J.; Dasarathy, S. Hypovitaminosis D is associated with increased whole body fat mass and greater severity of non-alcoholic fatty liver disease. Liver Int. 2014, 34, e118-e127. [CrossRef] [PubMed]

16. Rhee, E.J.; Kim, M.K.; Park, S.E.; Park, C.Y.; Baek, K.H.; Lee, W.Y.; Kang, M.I.; Park, S.W.; Kim, S.W.; Oh, K.W. High serum vitamin $\mathrm{D}$ levels reduce the risk for nonalcoholic fatty liver disease in healthy men independent of metabolic syndrome. Endocr. J. 2013, 60, 743-752. [CrossRef]

17. Liu, T.; Xu, L.; Chen, F.H.; Zhou, Y.B. Association of serum vitamin D level and nonalcoholic fatty liver disease: A meta-analysis. Eur J. Gastroenterol. Hepatol. 2020, 32, 140-147. [CrossRef] [PubMed]

18. Jaruvongvanich, V.; Ahuja, W.; Sanguankeo, A.; Wijarnpreecha, K.; Upala, S. Vitamin D and histologic severity of nonalcoholic fatty liver disease: A systematic review and meta-analysis. Dig. Liver Dis. 2017, 49, 618-622. [CrossRef]

19. Patel, Y.A.; Henao, R.; Moylan, C.A.; Guy, C.D.; Piercy, D.L.; Diehl, A.M.; Abdelmalek, M.F. Vitamin D is not associated with severity in NAFLD: Results of a paired clinical and gene expression profile analysis. Am. J. Gastroenterol. 2016, 111, 1591-1598. [CrossRef]

20. Chalasani, N.; Younossi, Z.; Lavine, J.E.; Diehl, A.M.; Brunt, E.M.; Cusi, K.; Charlton, M.; Sanyal, A.J. The diagnosis and management of non-alcoholic fatty liver disease: Practice guideline by the American Gastroenterological Association, American Association for the Study of Liver Diseases, and American College of Gastroenterology. Gastroenterology 2012, 142, 1592-1609. [CrossRef]

21. Park, H.E.; Lee, H.; Choi, S.Y.; Kwak, M.S.; Yang, J.I.; Yim, J.Y.; Chung, G.E. Clinical significance of hepatic steatosis according to coronary plaque morphology: Assessment using controlled attenuation parameter. J. Gastroenterol. 2019, 54, 271-280. [CrossRef] [PubMed]

22. Slomski, A. IOM endorses vitamin D, calcium only for bone health, dispels deficiency claims. JAMA 2011, 305, 453-456. [CrossRef]

23. Norman, A.W. From vitamin D to hormone D: Fundamentals of the vitamin D endocrine system essential for good health. Am. J. Clin. Nutr. 2008, 88, 491s-499s. [CrossRef]

24. Sandrin, L.; Fourquet, B.; Hasquenoph, J.M.; Yon, S.; Fournier, C.; Mal, F.; Christidis, C.; Ziol, M.; Poulet, B.; Kazemi, F.; et al. Transient elastography: A new noninvasive method for assessment of hepatic fibrosis. Ultrasound Med. Biol. 2003, 29, $1705-1713$. [CrossRef] [PubMed]

25. Boursier, J.; Zarski, J.P.; de Ledinghen, V.; Rousselet, M.C.; Sturm, N.; Lebail, B.; Fouchard-Hubert, I.; Gallois, Y.; Oberti, F.; Bertrais, S.; et al. Determination of reliability criteria for liver stiffness evaluation by transient elastography. Hepatology 2013, 57, 1182-1191. [CrossRef]

26. Eddowes, P.J.; Sasso, M.; Allison, M.; Tsochatzis, E.; Anstee, Q.M.; Sheridan, D.; Guha, I.N.; Cobbold, J.F.; Deeks, J.J.; Paradis, V.; et al. Accuracy of FibroScan controlled attenuation parameter and liver stiffness measurement in assessing steatosis and fibrosis in patients with nonalcoholic fatty liver disease. Gastroenterology 2019, 156, 1717-1730. [CrossRef]

27. Wang, D.; Lin, H.; Xia, M.; Aleteng, Q.; Li, X.; Ma, H.; Pan, B.; Gao, J.; Gao, X. Vitamin D levels are inversely associated with liver fat content and risk of non-alcoholic fatty liver disease in a Chinese middle-aged and elderly population: The Shanghai Changfeng Study. PLOS ONE 2016, 11, e0157515.

28. Barchetta, I.; Cimini, F.A.; Cavallo, M.G. Vitamin D and metabolic dysfunction-associated fatty liver disease (MAFLD): An update. Nutrients 2020, 12, 3302. [CrossRef] [PubMed]

29. Kromrey, M.L.; Ittermann, T.; Berning, M.; Kolb, C.; Hoffmann, R.T.; Lerch, M.M.; Völzke, H.; Kühn, J.P. Accuracy of ultrasonography in the assessment of liver fat compared with MRI. Clin. Radiol. 2019, 74, 539-546. [CrossRef] [PubMed]

30. Park, H.E.; Lee, H.; Choi, S.Y.; Kwak, M.S.; Yang, J.I.; Yim, J.Y.; Chung, G.E. Usefulness of controlled attenuation parameter for detecting increased arterial stiffness in general population. Dig. Liver Dis. 2018, 50, 1062-1067. [CrossRef]

31. Mikolasevic, I.; Poropat, G.; Filipec Kanizaj, T.; Skenderevic, N.; Zelic, M.; Matasin, M.; Vranic, L.; Kresovic, A.; Hauser, G. Association between gastroesophageal reflux disease and elastographic parameters of liver steatosis and fibrosis: Controlled attenuation parameter and liver stiffness measurements. Can. J. Gastroenterol. Hepatol. 2021, 2021, 6670065.

32. Li, L.; Zhang, L.; Pan, S.; Wu, X.; Yin, X. No significant association between vitamin D and nonalcoholic fatty liver disease in a Chinese population. Dig. Dis. Sci. 2013, 58, 2376-2382. [CrossRef]

33. LeFevre, M.L. Screening for vitamin D deficiency in adults: U.S. Preventive Services Task Force recommendation statement. Ann. Intern. Med. 2015, 162, 133-140. [CrossRef]

34. Rhee, S.Y.; Hwang, Y.C.; Chung, H.Y.; Woo, J.T. Vitamin D and diabetes in Koreans: Analyses based on the Fourth Korea National Health and Nutrition Examination Survey (KNHANES), 2008-2009. Diabet. Med. 2012, 29, 1003-1010. [CrossRef] [PubMed] 
35. Cimini, F.A.; Barchetta, I.; Carotti, S.; Bertoccini, L.; Baroni, M.G.; Vespasiani-Gentilucci, U.; Cavallo, M.G.; Morini, S. Relationship between adipose tissue dysfunction, vitamin $\mathrm{D}$ deficiency and the pathogenesis of non-alcoholic fatty liver disease. World $J$. Gastroenterol. 2017, 23, 3407-3417. [CrossRef]

36. Roth, C.L.; Elfers, C.T.; Figlewicz, D.P.; Melhorn, S.J.; Morton, G.J.; Hoofnagle, A.; Yeh, M.M.; Nelson, J.E.; Kowdley, K.V. Vitamin D deficiency in obese rats exacerbates nonalcoholic fatty liver disease and increases hepatic resistin and Toll-like receptor activation. Hepatology 2012, 55, 1103-1111. [CrossRef]

37. Barchetta, I.; De Bernardinis, M.; Capoccia, D.; Baroni, M.G.; Fontana, M.; Fraioli, A.; Morini, S.; Leonetti, F.; Cavallo, M.G. Hypovitaminosis D is independently associated with metabolic syndrome in obese patients. PLoS ONE 2013, 8, e68689.

38. Ock, S.Y.; Ha, K.H.; Kim, B.K.; Kim, H.C.; Shim, J.S.; Lee, M.H.; Yoon, Y.M.; Kim, D.J. Serum 25-hydroxyvitamin d concentration is independently inversely associated with insulin resistance in the healthy, non-obese Korean population. Diabetes Metab. J 2016, 40, 367-375. [CrossRef] [PubMed]

39. Cefalo, C.M.A.; Conte, C.; Sorice, G.P.; Moffa, S.; Sun, V.A.; Cinti, F.; Salomone, E.; Muscogiuri, G.; Brocchi, A.A.G.; Pontecorvi, A.; et al. Effect of Vitamin D supplementation on obesity-induced insulin resistance: A double-blind, randomized, placebo-controlled trial. Obesity 2018, 26, 651-657. [CrossRef] [PubMed]

40. Pirgon, O.; Cekmez, F.; Bilgin, H.; Eren, E.; Dundar, B. Low 25-hydroxyvitamin D level is associated with insulin sensitivity in obese adolescents with non-alcoholic fatty liver disease. Obes Res. Clin. Pract. 2013, 7, e275-e283. [CrossRef] [PubMed]

41. Beilfuss, A.; Sowa, J.P.; Sydor, S.; Beste, M.; Bechmann, L.P.; Schlattjan, M.; Syn, W.K.; Wedemeyer, I.; Mathé, Z.; Jochum, C.; et al. Vitamin D counteracts fibrogenic TGF- $\beta$ signalling in human hepatic stellate cells both receptor-dependently and independently. Gut 2015, 64, 791-799. [CrossRef] [PubMed]

42. Chon, Y.E.; Jung, K.S.; Kim, S.U.; Park, J.Y.; Park, Y.N.; Kim, D.Y.; Ahn, S.H.; Chon, C.Y.; Lee, H.W.; Park, Y.; et al. Controlled attenuation parameter (CAP) for detection of hepatic steatosis in patients with chronic liver diseases: A prospective study of a native Korean population. Liver Int. 2014, 34, 102-109. [CrossRef] [PubMed] 